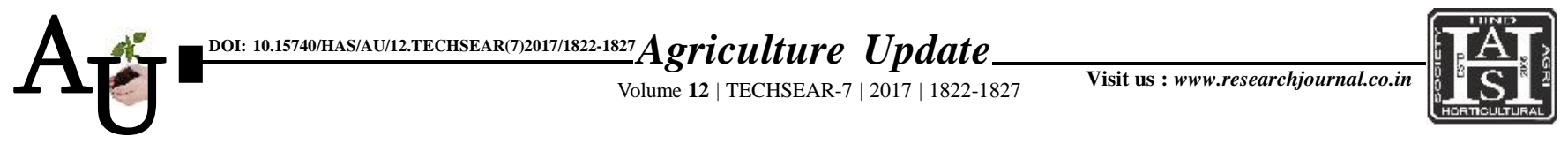

\title{
Research Article: Knowledge and adoption about dairy management practices of farmers in Wardha district
}

\section{Q VIJAYASHRI CHANDANKAR, TRUPTI RATHOD, M.K. RATHOD AND N.P. JANGWAD}

Article Chronicle:

Received :

19.07.2017;

Accepted :

03.08.2017

$\underline{\text { KEY WoRDS : }}$

Knowledge, Adoption, Dairy practices

Author for correspondence :

\section{VIJAYASHRI}

CHANDANKAR

Department of

Extension Education,

College of Agriculture,

NAGPUR (M.S.) INDIA

Email :

vijayshrichandankar@ gmail.com

See end of the article for authors' affiliations
SUMMARY : The present study was conducted in Wardha district of Maharashtra State in the Vidarbha region. For the study descriptive design namely exploratory research design was used. After critical analysis it was observed that, 99.00 per cent of the respondents had high level knowledge about dairy management practices while 59.00per cent farmers have adopted at medium level. In the mean index value highest knowledge was observed in breeding management practices i.e. 100.00 per cent followed by 93.50 and 83.16 per cent housing, cleaning and health practices, respectively. While, in case of adoption 79.66 average adoption of cleaning management practice was observed. In relational analysis land holding, extension contacts, and annual income were the variables found positively and significantly correlated with knowledge and adoption of dairy management practices.

How to cite this article : Chandankar, Vijayashri, Rathod, Trupti, Rathod, M.K. and Jangwad, N.P. (2017). Knowledge and adoption about dairy management practices of farmers in Wardha district. Agric. Update, 12(TECHSEAR-7) : 1822-1827; DOI: 10.15740/HAS/AU/12.TECHSEAR(7)2017/1822-1827. 